\title{
Why do pictures produce priming on the word-fragment completion test? A study of encoding and retrieval factors
}

\author{
MARY SUSAN WELDON \\ University of California, Santa Cruz, California \\ and \\ JULIE L. JACKSON-BARRETT \\ University of Nevada, Reno, Nevada
}

\begin{abstract}
Three experiments examined why pictures produce priming on the word-fragment completion test, despite the fact that there is no match between the physical features of the picture and the word fragment. Pictures and words were presented as primes, and performance on the wordfragment completion test was measured; encoding and retrieval conditions were varied. Experiments 1 and 2 examined the role of picture labeling by increasing the presentation rate and by introducing a shadowing task during encoding; labeling appears to play a role in priming. In Experiment 3, the word fragments were presented for $500 \mathrm{msec}$, and subjects were required to provide a solution immediately. Word priming was unaffected, but picture priming was eliminated, suggesting that word fragments enable efficient recovery of perceptually similar primes (i.e., words), but slower and less direct recovery of conceptually similar but physically dissimilar primes (i.e., pictures).
\end{abstract}

Recent work examining the nature of priming on implicit tests ${ }^{1}$ has demonstrated that the similarity between the encoding and retrieval tasks is an important determinant of the amount of priming observed (e.g., Blaxton, 1989; Masson \& MacLeod, 1992; E. R. Smith \& Branscombe, 1988; Srinivas \& Roediger, 1990; Weldon \& Roediger, 1987). Extending a distinction elaborated by Jacoby (1983), Roediger and colleagues have hypothesized that encoding and retrieval operations can be roughly classified according to the degree to which they engage predominantly conceptual or perceptual processing (e.g., Roediger, 1990; Roediger \& Blaxton, 1987b; Roediger, Weldon, \& Challis, 1989).

Conceptual and perceptual processing can be manipulated during both encoding and testing. During encoding, for example, when subjects generate a target word from a conceptually related clue (e.g., hot-c___ $)$, they engage in considerably more conceptual processing than when they read the target word without any conceptual context (e.g., $\mathrm{xxx}-$ cold), which engages relatively more perceptual processing (Jacoby, 1983). Other manipulations of

This research was supported by a grant from the Division of Social Sciences and by a Faculty Research Grant from the University of California, Santa Cruz. We would like to thank Samantha Faber, Berry Reyna, and Herbert Colston for their assistance in collecting the data. We also thank Larry Jacoby, Daniel Schacter, Henry L. Roediger, III, and an anonymous reviewer for their helpful comments on an earlier version of the manuscript. Correspondence should be addressed to M. S. Weldon, Department of Psychology, Kert Hall, University of California, Santa Cruz, CA 95064 (e-mail: weldon@cats.ucsc.edu). conceptual processing at encoding include level of processing and organization of the word list (e.g., Hamann, 1990; Rappold \& Hashtroudi, 1991; Srinivas \& Roediger, 1990). Other ways of manipulating perceptual processing include changing modality, typeface, or orthographic properties of the study relative to the test stimulus (e.g., Gardiner, Dawson, \& Sutton, 1989; Glisky \& Rabinowitz, 1985; Graf \& Ryan, 1990; Kolers, 1975; Roediger \& Blaxton, 1987a; Schacter \& Graf, 1989).

Analogous to encoding tasks, both implicit and explicit memory tests also can vary in the degree to which they involve perceptual or conceptual processing. Conceptual tests are sensitive to the encoding of meaning, thus orienting tasks that engage more meaningful processing produce better performance on these tests. However, manipulations of stimulus surface features (e.g., modality of presentation) have little or no effect on these tests. Examples of implicit conceptual tests include category production, word association, and answering general knowledge questions (Blaxton, 1989; Hamann, 1990; Rappold \& Hashtroudi, 1991; Srinivas \& Roediger, 1990). Examples of explicit conceptual tests include free recall, conceptual cued recall, and recognition.

In contrast to conceptually driven tests, perceptual tests are most sensitive to the manner in which the surface features of the target are encoded. In general, the more similar the surface features of the encoding and test stimulus, the more priming achieved (e.g., Jacoby \& Dallas, 1981; Rajaram \& Roediger, in press; Roediger \& Blaxton, 1987b; but see Masson \& MacLeod, 1992). On the other hand, conceptual manipulations such as level of process- 
ing have little or no effect on these tests (Jacoby \& Dallas, 1981; Roediger, Weldon, Stadler, \& Riegler, 1992; but see Challis \& Brodbeck, 1992). Examples of implicit perceptual tests are perceptual identification (identifying briefly presented words), word-fragment completion (solving words with missing letters, e.g., _e__nu_ as peanut), and word-stem completion (completing pea with the first word that comes to mind).

Roediger (1990; Roediger et al., 1989) has espoused the principle of transfer-appropriate processing to account for these results, suggesting that the goodness of any encoding operation depends on the processing requirements of the test; therefore, memory performance will be a function of the overlap between encoding and retrieval processes (Morris, Bransford, \& Franks, 1977). Although this general principle holds over a wide range of testing situations, critics of Roediger's framework point to the fact that conceptual encoding manipulations can affect the amount of priming obtained on perceptual tests (Bassili, M. C. Smith, \& MacLeod, 1989; Hirshman, Snodgrass, Mindes, \& Feenan, 1990; Masson \& MacLeod, 1992). For example, words that are inferred from sentences but are not actually read produce priming on the word-stem completion test (Bassili et al., 1989), and changing the meaning of a homograph or varying context words between encoding and test reduces priming on the word-stem completion and word-fragment completion tests (Graf \& Schacter, 1985; Lewandowsky, Kirsner, \& Bainbridge, 1989; Masson \& Freedman, 1990; Weldon, 1991). Masson and MacLeod have suggested that the integration of the target with its encoding context modulates the amount of priming obtained on the perceptual identification test, which reflects the influence of conceptual processing on a perceptual test. Weldon and colleagues (Weldon, Roediger, \& Challis, 1989) have suggested that the presence of context words at test makes the test more conceptually driven, thus one would expect to find an influence of conceptual processing in this situation. Nevertheless, not all of the experiments that have obtained effects of conceptual processing have included context words at test, hence a further explanation is needed.

Such findings suggest the need to analyze more carefully the roles of different kinds of processes in implicit perceptual tests. Why do primes that bear no physical similarity to the test stimulus produce any priming at all? In what manner do other types of processing affect perceptual priming? The purpose of the work reported here is to examine the role of perceptual and conceptual factors in priming on the word-fragment completion test.

Weldon has explored some aspects of this issue elsewhere (Weldon, 1991; Weldon, in press; Weldon \& Roediger, 1987), and the goal of the research reported here was to focus on the particular problem of why pictures produce priming on the word-fragment completion test. Across several experiments, Weldon and colleagues (Roediger et al., 1992; Weldon, in press; Weldon \& Roediger, 1987; Weldon et al., 1989) have repeatedly found that although words produce substantially more priming than do pictures on this test, pictures consistently produce small but significant amounts of priming (about .20 for words, $.05-.07$ for pictures). Others also have obtained significant priming from pictures on verbal, perceptual tasks (Brown, Neblett, Jones, \& Mitchell, 1991; Kirsner, Milech, \& Stumpfel, 1986; Kroll \& Potter, 1984). Pictures provide an interesting means for studying priming on the word-fragment completion test because they share no physical features with the target words yet still refer to the same concept. Therefore, they have the potential to provide insight into how nonperceptual factors contribute to priming.

Originally it seemed that the most likely explanation for the picture-priming effect in word-fragment completion was that subjects labeled some proportion of the pictures during the encoding phase. This is an instantiation of the lexical access hypothesis, which suggests that priming on verbal tests requires that the prime access the same lexical unit represented by the test word (Weldon, 1991). For example, lexical access might either overtly or covertly activate word-level information, such as orthographic or phonological features, which could help in completing the word fragments.

To test the hypothesis that labeling underlies picture priming of word fragments, Weldon and Roediger (1987; Experiments 2 and 3 ) conducted a variety of manipulations intended to vary the probability that subjects would label the pictures during encoding. For example, in Experiment 2 , subjects in the critical condition were told that they would receive a difficult picture-discrimination test in which they would have to decide which of two very similar pictures they had seen in the study phase. This condition was intended to reduce labeling by focusing subjects' attention on the physical features of the picture. In other conditions across Experiments 2 and 3, subjects saw the picture and generated the label silently, mouthed it without saying it aloud, or named it out loud. If labeling was the source of the priming, then the amount of priming should have varied with the degree of labeling. However, across five different conditions intended to vary labeling, priming varied between only $5 \%$ and $8 \%$, and none of the differences were significant. In the condition intended to minimize labeling, priming was $6 \%$.

Weldon and Roediger suggested that labeling is not the source of picture priming on the word-fragment completion test and that the test might be slightly sensitive to conceptual processing, an idea supported in later research (Weldon, 1991; also see similar arguments regarding other perceptual tasks by Bassili et al., 1989; Brown et al., 1991; Hirshman et al., 1990; Masson \& MacLeod, 1992; Schacter \& Graf, 1989; Toth \& Hunt, 1990).

The aim of this research is to examine further the basis of picture priming on the word-fragment completion test by assessing the role of encoding and retrieval factors. In three experiments, subjects studied mixed lists of pictures and words, performed a 7 -min distractor test, and then took a word-fragment completion test. Finally, the subjects took a free-recall test as a manipulation check. 
Experiments 1 and 2 examined encoding factors by varying the rate at which the primes were presented during the study phase and by incorporating a shadowing task during the study phase. Experiment 3 examined retrieval factors by varying the amount of time the fragment was exposed during the test phase.

Some comments about the use of the free-recall test in these experiments are in order. Free recall has been classified as an explicit, conceptually driven test, and a large volume of literature indicates that pictures are typically remembered better than words on this test. Possible explanations include dual coding theory (Paivio, 1971, 1986, 1991), which proposes that pictures are more likely than words to activate both logogens and imagens, and that such dual coding increases the probability of recall. Other interpretations suggest that pictures contact meaning codes more directly than do words (e.g., Nelson's sensory-semantic model, 1979; Potter \& Faulconer, 1975; M. C. Smith \& Magee, 1980). These interpretations are consistent with the principle of transfer-appropriate processing because pictures are alleged to elicit more elaborative and meaningful processing, and hence produce superior performance on a conceptually driven test (for more extensive discussion, see Weldon \& Roediger, 1987; Weldon et al., 1989).

In the present experiments, the free-recall test is included to check the effects of the encoding manipulations on a conceptually driven test on which pictures are expected to produce better performance than are words. Labeling manipulations have been shown to have significant effects on free recall, while having minimal effects on the word-fragment completion test (Weldon \& Roediger, 1987). For example, Weldon and Roediger (Experiment 2) found that requiring subjects to generate a label as opposed to preparing for a picture-discrimination task had a large effect on free recall (.39 vs. .29, respectively) but no effect on fragment completion priming. Also, requiring subjects to label every picture increases free recall relative to making judgments about the picture's size (D'Agostino, O'Neill, \& Paivio, 1977) or about the time it would take to draw it (Durso \& Johnson, 1980). Therefore, the free-recall data will help assess the potency of the labeling manipulations employed here. These data must be interpreted cautiously because this test was administered after the word-fragment completion test and performance may be contaminated. However, Weldon and Roediger demonstrated that dissociations obtained between the free-recall and the word-fragment completion tests persist even when free recall follows word-fragment completion, a finding replicated here. Although the recall data must be viewed carefully, they still provide useful interpretive information.

\section{EXPERIMENT 1}

Experiment 1 was conducted to examine how encoding factors affect picture priming of word fragments. Weldon and Roediger's (1987) claim that picture labeling does not underlie performance needs further support because it is difficult to verify that the manipulation they used, which led subjects to expect a visual discrimination test, really did suppress labeling. For example, in order to encode the pictorial details, subjects may have adopted a strategy in which they described the item to themselves and generated the label, such as "The windmill has four large blades on a small triangular building'" Experiment 1 was designed to affect picture labeling more directly.

In Experiment 1, the amount of time the picture and word slides were exposed during the encoding phase was varied ( $5 \mathrm{sec}$ vs. $250 \mathrm{msec}$ ) to affect the probability that pictures could be labeled. Paivio $(1971,1986)$ has proposed that pictures are remembered better than words, because when subjects view pictures, they are more likely to generate a corresponding label or name, and hence the item is dually coded, but subjects are less likely to generate an image that corresponds to a word. Dual codes increase the probability of retrieving the target item. Among a vast amount of evidence in support of the dual code hypothesis, Paivio and Csapo (1969) have reported that when items are presented rapidly during encoding, the picture superiority effect disappears; presumably, subjects do not have time to label the pictures, and so the mnemonic advantage of the dual code that underlies the picture superiority effect is eliminated (cf. Intraub, 1979).

We adopted this strategy in Experiment 1. At rapid presentation rates, subjects should not have sufficient time to label the pictures. If labeling accounts for picture priming of word fragments, then presenting pictures rapidly should eliminate priming.

\section{Method}

Subjects and Design. The subjects were 72 undergraduate students from the University of California, Santa Cruz, who participated either for course credit or for $\$ 5$. The experiment comprised a 2 (presentation time: $5 \mathrm{sec}$ vs. $250 \mathrm{msec}$ ) $\times 3$ (prime type: word, picture, nonstudied) mixed design, with presentation time varied between subjects and prime type varied within subjects. Thirty-six subjects served in each presentation-time condition. All items were properly counterbalanced so that they appeared an equal number of times in all conditions in the experiment.

Materials. The materials were $\mathbf{4 2}$ target items taken from the Snodgrass and Vanderwart (1980) set and similar items previously prepared by Weldon and Roediger (1987). These were black-andwhite drawings of familiar objects and animals, with a moderate amount of detail. There were two slides for each item, one containing the drawing, and the other containing the name of the target. Items had been normed so that agreement between the intended name and the subject-generated name for the pictures averaged $96 \%$.

The targets were divided into three sets of 14 items that were rotated through the word, picture, and nonstudied conditions to create three different study lists. Within each list, the pictures and words were randomly mixed with the restriction that no more than three pictures or words appeared sequentially. Four buffer items (two pictures, two words) were placed at the beginning and end of each list; these items were not scored on the tests.

The word-fragment completion test contained 50 fragments, 42 targets, and 8 fillers. Because one third of the targets were not studied, there was a total of 22 nonstudied and 28 studied items on the test for each individual. Each fragment had a unique solution.

Procedure. The subjects were tested in groups of 1-4. They were told that they were helping prepare materials for future experiments 
and were not told that they would receive a memory test. They were instructed that on the first task, they would see a series of pictures and words on slides and that they should pay attention to each one. The subjects were told how fast the items would be presented. Slides were presented on a Kodak carousel slide projector and projected onto a slide screen at the front of the room, about $12 \mathrm{ft}$ in front of the subjects. The items were presented for either $5 \mathrm{sec}$ or $250 \mathrm{msec}$, with a 750 -msec change time between slides. After the slides were presented, the subjects worked on mazes for $7 \mathrm{~min}$ as a distractor task.

The subjects then received the word-fragment completion test, but they were not told that some of the fragments were related to the slides. They were allowed $12 \mathrm{sec}$ to solve each fragment, and the fragment was visible during the entire interval. They were not allowed to work ahead or go back to any fragments. They used a cover sheet to conceal the upcoming fragments.

Next, the subjects received a free-recall test on which they were given $7 \mathrm{~min}$ to recall as many word and picture slides as possible. Finally, they received a questionnaire asking whether they had labeled the pictures during encoding.

\section{Results and Discussion}

Word-fragment completion. Average priming scores in each condition are presented in Table 1 , and the average baseline performance in each group is presented in parentheses. Priming scores were computed by subtracting the baseline scores from the total number correct in each group. In all experiments, results are reported at $p<$ .05 , unless otherwise indicated.

The data in Table 1 suggest that the faster presentation rate had no effect on priming by either words or pictures, and an analysis of variance (ANOVA) confirms this. There was a main effect of prime type $[F(1,70)=21.53$, $M S_{\mathrm{c}}=.011$, exhibiting the usual finding that words produce more priming than do pictures on this test. However, there was no main effect of prime presentation rate $(F<1)$ and no interaction between type of prime and presentation rate $(F<1)$. Words and pictures both produced significant levels of priming $[t(71)=7.22, t(71)=$ 3.27 , respectively]. Therefore, limiting exposure time during the study phase did not decrease the number of priming pictures produced.

Table 1

Effects of Encoding and Retrieval Variables on Word-Fragment Completion Priming in Experiments 1-3

\begin{tabular}{cccc}
\hline & \multicolumn{3}{c}{ Prime Type } \\
\cline { 2 - 4 } Study Time & Word & Picture & $\begin{array}{c}\text { Nonstudied } \\
\text { Baseline }\end{array}$ \\
\hline
\end{tabular}

$\begin{array}{lccc} & \text { Experiment } 1: \text { Study Time } \\ 5 \mathrm{sec} & .18 & .07 & (.27) \\ 250 \mathrm{msec} & .16 & .08 & (.28)\end{array}$

Experiment 2: Shadowing and Study Time

$\begin{array}{lrrr}5 \mathrm{sec} & .09 & .00 & (.30) \\ 1.5 \mathrm{sec} & .11 & .02 & (.28) \\ 250 \mathrm{msec} & -.04 & .00 & (.33)\end{array}$

Experiment 3: 500-msec Fragment-Exposure Time $5 \mathrm{sec}$ .20 .01

Note-Priming on the word-fragment completion test was computed by subtracting the nonstudied baseline (presented in parentheses) from the total proportion correct in the picture and word conditions.
Table 2

Effects of Encoding and Retrieval Variables on Free Recall in Experiments 1-3

\begin{tabular}{lcc}
\multicolumn{3}{c}{ on Free Recall in Experiments 1-3 } \\
\cline { 2 - 3 } Study Time & Word & Picture \\
\hline & Experiment 1 & .44 \\
$5 \mathrm{sec}$ & .28 & .31 \\
$250 \mathrm{msec}$ & .16 & \\
& Experiment 2 & .10 \\
$5 \mathrm{sec}$ & .08 & .09 \\
$1.5 \mathrm{sec}$ & .06 & .06 \\
$250 \mathrm{msec}$ & .08 & \\
& Experiment 3 & .35 \\
\hline $5 \mathrm{sec}$ & .28 &
\end{tabular}

One possible problem with Experiment 1 is that the exposure time manipulation did not effectively reduce labeling. To eliminate the picture superiority effect in their experiment, Paivio and Csapo (1969) presented items at the rate of $5.3 \mathrm{items} / \mathrm{sec}$, whereas the fastest we could present items on our equipment was 1 item/sec (250-msec exposure time, 750-msec slide-change time). We asked the subjects whether they had labeled the pictures as they were presented and, if so, what percentage of the pictures they had labeled. Comparing the presentation conditions, in the 5 -sec and 250 -msec conditions, $94 \%$ versus $88 \%$ of the subjects, respectively, reported labeling at least one picture, and estimates of the number of pictures labeled averaged $77 \%$ versus $70 \%$, respectively. Of course, such introspective reports must be viewed cautiously, since subjects are not necessarily capable of estimating this behavior accurately. Nevertheless, these data do not indicate that the exposure time manipulation had a very large effect on the subjects' tendency to label the pictures. This problem was addressed in Experiment 2.

Free recall. Free-recall data are presented in Table 2, and provide an interesting contrast to the results on the word-fragment completion test. Although presentation rate had no effect on word-fragment completion, free recall was significantly depressed when pictures and words were presented rapidly. The results of the ANOVA reveal a main effect of presentation rate, with shorter study times resulting in worse recall $\left[F(1,70)=20.45, M S_{\mathrm{e}}=.03\right]$. However, the picture superiority effect was not eliminated; pictures produced better recall than did words $\left[F(1,70)=57.50, M S_{e}=.02\right]$. There was no interaction between these factors $(F<1)$.

Thus, presentation rate had a detrimental effect on free recall but no effect on word-fragment completion. However, the picture advantage in free recall was not eliminated at the fast presentation time, which would have been expected if labeling had been successfully suppressed.

\section{EXPERIMENT 2}

As noted above, it is possible that the manipulation of presentation rate in Experiment 1 was not powerful 
enough to suppress labeling of pictures. Experiment 2 was designed to introduce an even stronger technique for suppressing labeling by requiring the subjects to shadow an unrelated passage while they viewed the picture and word slides. The subjects listened through headphones to a passage about nonverbal communication and were required to repeat the passage out loud. This task should limit their ability to access other verbal codes simultaneously. To add to the strength of the encoding manipulation, presentation rate was again varied so that picture and word slides were presented for $5 \mathrm{sec}, 1.5 \mathrm{sec}$, or $250 \mathrm{msec}$ each.

\section{Method}

Subjects and Design. The subjects were 108 undergraduates at the University of California, Santa Cruz, who participated either for course credit or for $\$ 5$. All were native English speakers who had either normal or corrected vision and had not participated in the previous experiment. The design was a 3 (presentation time: $5 \mathrm{sec}, 1.5 \mathrm{sec}, 250 \mathrm{msec}$ ) $\times 3$ (prime type: word, picture, nonstudied) mixed design, with presentation time manipulated between subjects and prime type manipulated within subjects. Thirty-six subjects served in each presentation-time condition. Items were appropriately counterbalanced so that each item appeared in each condition an equal number of times.

Materials. The study lists and test were identical to those used in Experiment 1. For the shadowing task, a passage about nonverbal communication was recorded and played to the subjects over headphones. Additional picture and word slides were used for a practice phase described below.

Procedure. The subjects were told that the purpose of the experiment was to help prepare materials for future experiments. They were then introduced to the shadowing task. They were told that the main purpose of this task was to see how well people can repeat auditorily presented information and that the experimenter would be listening and recording errors. (The experimenter held a clipboard and pencil and watched the subjects during the shadowing tasks to maintain this illusion.) They were also told they would receive several different practice tasks before performing the task of actual interest.

In the first practice task, the subjects listened to the tape and tried to shadow it for about $2 \mathrm{~min}$. The experimenter then checked to make sure the subjects felt comfortable with the task. The subjects were then given a second short paragraph to practice shadowing. Next, the experimenter told the subjects that in the third practice task, slides would be presented during the shadowing task, and although it was important that they continue to shadow accurately, it was also important that they look at the slides and not miss any. They were told how fast the slides would be presented $(5 \mathrm{sec}$, $1.5 \mathrm{sec}$, or $250 \mathrm{msec}$ each, with a 750 -msec change time). The slides were presented on the same equipment used in Experiment 1. After the subjects shadowed the first three sentences, the experimenter began the slide presentation and showed 12 practice slides. Finally, the subjects were told that they would now perform the actual task in which a longer list of slides would be presented while they shadowed. They were again reminded that they should shadow accurately but that they should also make sure that they attended to every slide. The experimenter started the tape, and after the subjects had shadowed the first three sentences, the experimenter started the target slide presentation.

At the end of the slide presentation, the subjects removed their headphones and were given $7 \mathrm{~min}$ to complete various mazes as a distractor task. The subjects were then given the word-fragmentcompletion and free-recall tests in the same manner as in Experiment 1 and finally were given the postexperiment questionnaire.

\section{Results and Discussion}

Word-fragment completion. Average priming and baseline scores are presented in Table 1 . The data reveal that shadowing did in fact eliminate priming from pictures, suggesting that labeling may underlie picture priming. However, this interpretation is complicated somewhat by the detrimental effect of shadowing on word priming as well. Relative to performance in Experiment 1, priming from words is reduced.

An ANOVA on the priming scores revealed a significant main effect of prime type $\left[F(1,105)=12.47, M S_{\mathrm{e}}=\right.$ $.01]$, indicating that words produced more priming than did pictures. The main effect of presentation rate was marginally significant $\left[F(2,105)=2.35, M S_{\mathrm{e}}=.05, p=\right.$ .10]. The interaction between type of prime and presentation rate was significant $\left[F(2,105)=9.13, M S_{e}=.01\right]$, reflecting the fact that whereas pictures produced no priming in any condition, words produced priming at the two slowest presentation rates ( 5 and $1.5 \mathrm{sec}$ per item) but not at the fastest rate ( $250 \mathrm{msec}$ per item). An ANOVA examining word priming (word vs. nonstudied) at the three rates confirmed that words produced significant priming $\left[F(1,105)=9.71, M S_{\mathrm{e}}=.02\right]$, qualified by an interaction between prime and presentation rate $[F(2,105)=$ $\left.6.75, M S_{\mathrm{e}}=.05\right]$.

Additional evidence that labeling was reduced with the shadowing manipulation comes from the subjective reports of the subjects. The percentages of subjects who reported that they had labeled at least one picture were $53 \%, 50 \%$, and $47 \%$ in the $5-\mathrm{sec}, 1.5-\mathrm{sec}$, and $250-\mathrm{msec}$ presentation times, respectively, dropping from $94 \%$ in the control condition in Experiment 1. The average proportions of pictures that the subjects reported they had labeled were $29 \%, 13 \%$, and $11 \%$, respectively, also representing a large drop from the average of $77 \%$ in Experiment 1. These introspective reports support the claim that subjects are less likely to label pictures when shadowing.

The shadowing task appears to have been sufficiently powerful to impair encoding of pictures and eliminate priming, even at the slowest presentation rate. However, the effects of the shadowing task were not selective. That is, shadowing appears to have interfered with the encoding of the target information for words as well as pictures, since performance for both conditions is depressed relative to Experiment 1. It seems appropriate to conclude that labeling contributes to picture priming on the wordfragment completion test, if one accepts the idea that shadowing interferes with lexical access. Accordingly, shadowing could also reduce word priming because it would impair lexical access for the words as well. However, words could continue to produce significant priming for a few reasons. First, even with shadowing, it probably is easier to read words than to generate labels of pictures, thus lexical access is still more probable for words. Second, because there is a large perceptual component to priming, the words would continue to have this advantage over pictures. 
It is possible that shadowing interrupted other encoding processes in addition to lexical access, so the decrement in performance cannot be isolated to the disruption of lexical access alone. If shadowing had affected picture priming but had not affected word priming, the argument that labeling plays the critical role in picture priming would be stronger. However, because shadowing impaired both word and picture priming, it is not entirely clear whether the effect is due only to the interruption of picture labeling or to more generalized interference with encoding. If the performance decrement is caused by general interference with encoding processes in addition to lexical access, an alternative to the lexical-access hypothesis is possible. That is, perceptual priming may require access to an abstract conceptual representation shared by both the word and picture, and the shadowing manipulation interfered with this process. Nevertheless, the evidence does suggest that labeling plays some role in picture priming on this test.

Free recall. The free-recall data presented in Table 2 are quite interesting in conjunction with the priming results. The picture superiority effect has effectively been eliminated with this manipulation; the main effect of study stimulus is not significant $[F(1,105)=2.58, p>.10]$. This finding suggests that the manipulation successfully eliminated labeling and is congruent with Paivio and Csapo's (1969) finding that the picture superiority effect disappears at very fast presentation rates that presumably do not allow time to access the pictures' names. In Experiment 2 , adding the shadowing manipulation during the slide presentation appears to have been powerful enough to mimic Paivio and Csapo's effect of rapid presentation.

The free-recall data in Experiment 2 would thus appear to suggest that labeling was reduced, and hence the lack of picture priming on the word-fragment-completion test could be interpreted as evidence that labeling is the cause of picture priming. However, as in the word-fragmentcompletion test, performance for both pictures and words was adversely affected, so shadowing may have produced other encoding deficits as well. Nevertheless, the fact that picture priming was eliminated whereas words still produced priming at the 5- and 1.5-sec presentation times does suggest that labeling or some aspect of lexical access plays a role in picture priming.

\section{EXPERIMENT 3}

Experiment 3 was conducted to determine whether retrieval processes play a role in picture priming of word fragments. ${ }^{2}$ We hypothesized that word-fragment completion may be perceptual or "data-driven" in the sense that it efficiently recapitulates perceptual processing that occurred during the study phase. For example, the orthographic information in the word fragment (e.g., _ame__a) is more directly associated with the visual form of the word camera than with the image of a camera. Thus, the fragment will be most readily completed if the encoding episode engaged visual processing of the word, because the cuing information in the fragment renders the word more recoverable than the picture.

Fragments might recover words relatively efficiently but might recover pictures less reliably and less efficiently. The fragments may be very weak cues for the pictures, but, given enough time, they may be capable of providing sufficient retrieval information to recover the originally encoded information. That is, fragments may recapitulate a prior encoding episode quickly if perceptually similar information was encoded (as in the case of visually presented word primes), but recovery of pictures will be slower and less direct because perceptually similar information was not encoded. Therefore, if fragments are exposed for a very brief period of time and subjects are required to respond immediately, picture priming of word fragments should not be observed because there will not have been enough time for the retrieval information to become effective in recovering the original picture prime.

The purpose of Experiment 3 was to examine the role of retrieval processes in picture priming of word fragments by testing the hypothesis that pictures are recovered more slowly than words. The subjects studied pictures and words for $5 \mathrm{sec}$ and were told to pay close attention to each item. They then received a word-fragment completion test on which fragments were presented tachistoscopically for $500 \mathrm{msec}$ each, and they were required to write a solution within $4 \mathrm{sec}$. It was predicted that picture priming would be eliminated but that word priming would continue to be significant.

\section{Method}

Subjects. The subjects were 33 undergraduate students at the University of California, Santa Cruz, who participated either for course credit or for \$5. All were native English speakers who had either normal or corrected vision and had not participated in the previous experiments.

Materials. The study lists and distractor tasks were identical to the ones used in Experiments 1 and 2. The word-fragment completion test was administered differently. All of the word fragments were presented on slides by a Kodak carousel projector for $500 \mathrm{msec}$, with presentation time controlled by a tachistoscopic shutter. The subjects were given a lined sheet of paper on which to write down their fragment solutions.

Procedure. The subjects were tested in groups of 1-3. The study phase and distractor tasks were conducted as in the 5-sec study condition in Experiment 1. During the test phase, the word fragments were presented on a slide screen for only $500 \mathrm{msec}$, and the subjects were allowed $4 \mathrm{sec}$ to write an answer before the next fragment was flashed. The task was very fast, and the subjects literally had time to write only the first word that came to mind in response to the fragment. It was necessary to restrict the writing time in this manner in order to ensure that the subjects did not have additional time to contemplate the solution to the fragment-we wanted them to answer only with the information that had become immediately available. Fragment exposure time was controlled by a tachistoscopic shutter, and the slides were advanced with an automatic timer.

\section{Results and Discussion}

Word-fragment completion. The priming scores and nonstudied baselines are presented in Table 1 and reveal that although priming from word primes was unaffected relative to Experiment 1, priming from pictures was vir- 
tually eliminated. An ANOVA revealed a main effect of prime type $\left[F(2,64)=31.59, M S_{\mathrm{e}}=.01\right]$. Words produced significant priming $[t(32)=6.4]$, but pictures did not $[t(32)=.24, p=.40$, one-tailed]. The baseline is lower than in Experiment 1, but this is not surprising; because subjects had so little time to see and solve the fragment, the overall level of performance would be expected to drop.

This is a very striking result and attests to the importance of retrieval processes in priming on this task. Specifically, the results support the idea that the word fragment is a very efficient cue for perceptually relevant information. Although the cue can access perceptually dissimilar information, two pieces of evidence indicate that it does so much less efficiently. First, the word fragment is a relatively weak cue for pictures, as indicated by the low level of priming generally obtained from pictures (about 5\%-7\%) as compared with words (about 20\%). Second, picture recovery occurs relatively more slowly, as indicated by the fact that when the fragment was exposed for only a brief period of time $(500 \mathrm{msec})$ and the subjects were forced to respond immediately, perceptually overlapping primes (visual words) continued to produce high levels of priming compared with pictures, which produced no priming.

Free recall. Proportions correct on the free recall test are presented in Table 2. An ANOVA revealed a significant picture superiority effect $\left[F(1,32)=4.16, M S_{\mathrm{e}}=\right.$ .02]. Note that one would not expect the retrieval effect observed on the word-fragment completion test to be observed on the free-recall test because the 500 -msec exposure time is a manipulation of response deadline on the fragment completion test only.

\section{GENERAL DISCUSSION}

These experiments were conducted to examine the factors that contribute to picture priming on the wordfragment completion test. Experiments 1 and 2 were designed to determine whether labeling contributes to the effect, and Experiment 2 did indicate that labeling plays a role. Experiment 3 was designed to assess the role of retrieval processes, and its results suggested that word fragments recover perceptually similar primes (visually presented words) more efficiently than perceptually dissimilar primes (pictures). Overall, the data provide useful information about the nature of perceptual priming, suggesting that both encoding and retrieval processes play a role in the occurrence of picture priming on the wordfragment completion task.

The fact that shadowing eliminated picture priming seems consistent with the lexical access hypothesis, which suggests that primes must access the lexical referent of the target in order to produce priming (Weldon, 1991). However, if labeling does play a role in priming, then why does performance not improve when subjects are explicitly instructed to label pictures, in the same way it improves in free recall (Weldon \& Roediger, 1987)? Per- haps subjects tend to label pictures spontaneously (as suggested by the subjective reports from Experiment 1), which provides the nominal lexical access needed to produce priming on the word-fragment completion test. Explicit instructions to label pictures might result in somewhat more elaborative processing than that which normally occurs with spontaneous labeling. This might affect a conceptually driven test such as free recall but not be of much value on a more perceptual test such as word-fragment completion. Therefore, although suppressing labeling may eliminate the necessary contact with the lexical code, encouraging labeling does not provide added benefits on word-fragment completion. This is speculative and begs the following question: If perceptual tests are sensitive to elaborative or conceptual processing, as has been argued here and elsewhere, then to what types of elaborative or conceptual processes are they sensitive? When can we expect to see effects of elaborative processing, and when can we not? Clearly, more work is needed in this area.

Experiment 3 provided clear evidence for the role of retrieval processes in the priming of word fragments. Fragment completion is more efficient when the prime is a word than when it is a picture. Reading the word engages graphemic processing that can be readily transferred to the task of resolving the fragment. In contrast, although the picture represents a concept similar to that of the word, it is perceptually dissimilar. Therefore, the processes engaged while viewing the picture are not readily recapitulated by the word fragment, and the fragment cannot be solved as quickly as it can with word primes.

To recover the picture, the fragment may provide some cuing information that operates relatively weakly and indirectly. For example, the orthographic or phonological information in the fragment may be associated with a longterm representation of the word, and the fragment may activate this representation. This activated word representation may in turn be associated with a conceptual or imaginal representation, which also becomes activated. The long-term lexical information or the imaginal information, or both, may then provide cuing information to help recover the picture that was encoded during the study episode. Through this mechanism, fragment-completion performance can be elevated over baseline levels, even when perceptually dissimilar items were studied at test. (Presumably, access to the long-term representations accounts for baseline performance alone.) However, this process would take longer than the recovery of a word that has perceptual features that can be accessed more directly by the fragment.

A second mechanism through which picture primes may result in relatively slower fragment completion involves a possible role of orthographic or phonological processing. For example, if some proportion of pictures are labeled as suggested by Experiments 1 and 2, orthographic or phonological information may be encoded, and the word fragment will share some of these properties. However, this encoded information will be relatively impoverished as compared with that encoded from visual 
word primes, and so it will take longer for the missing information in the word fragment to be assembled.

It is assumed that these retrieval processes can occur without conscious recollection, but conscious retrieval strategies may also play a role in picture priming of word fragments. That is, subjects may notice that the fragments on the test refer to the words and pictures they studied on the slides and use this information to help them solve difficult fragments. Explicit retrieval strategies may make more use of conceptual information, thus pictures can be retrieved. Again, this process would take longer than the direct access that can occur when the prime and test fragment are perceptually similar. Weldon et al. (1989) have demonstrated that even under explicit retrieval conditions, perceptual processes dominate performance on the wordfragment-completion test. Thus, the possibility that subjects are engaging in explicit retrieval does not undermine the claim that perceptual information is accessed more efficiently than nonperceptual information on a data-driven test; rather, it serves as one possible explanation of conceptual influences on a data-driven test.

Other bases for the relatively slower fragment resolution due to picture primes are possible, too, and these possibilities are elaborated further elsewhere (Weldon, in press). The important point is that the data presented here add definition to the concept of data-driven processing. Other work has amply demonstrated that perceptually similar primes increase the probability of successfully resolving the test stimuli on perceptual tests. Here, it is demonstrated that this resolution occurs more efficiently in the sense that the perceptual information is accessed before the nonperceptual information in order to resolve the fragment.

How do these results fit into current models of priming? Among several frameworks of interest are the activation account (e.g., Monsell, 1985; Morton, 1979), various episode-specific accounts (e.g., transfer-appropriate processing, Roediger, 1990; fluency of processing, Jacoby \& Brooks, 1984; Johnston, Dark, \& Jacoby, 1985; recruitment of operations, Masson \& Freedman, 1990), and the multiple memory systems account (e.g., Schacter, 1990, 1992; Tulving \& Schacter, 1990). In general, the activation of an abstract representation may play a role in priming, but as others have noted, the specificity of priming on perceptual tests cannot easily be explained by a model proposing that priming is due simply to the activation of abstract nodes (e.g., see discussions by Masson \& Freedman, 1990; Schacter, 1990).

Generally speaking, episode-specific views propose that during encoding, a stimulus is processed in a particular way, and priming arises when the test stimulus and task are sufficiently similar to the original encoding episode to result in more efficient or fluent processing of the test stimulus. The original encoding episode may be retrieved, albeit not consciously, and facilitate current processing. Although various theories differ in the degree to which they emphasize the relative importance of stimulus features, cognitive processes, and contextual factors, they share the assumption that the similarity between encoding and retrieval processes determines the level of priming obtained. Most recent episode-specific accounts of priming suggest that conceptual processing can support priming on perceptual tests (e.g., Bassili et al., 1989; Hirshman et al., 1990; Masson \& Freedman, 1990; Masson \& MacLeod, 1992; Schacter \& Graf, 1989; Toth \& Hunt, 1990; Weldon, 1991) and thus easily accommodate the finding that pictures produce priming on the wordfragment-completion test. Episode-specific views also can account for the role of lexical access in picture priming, which establishes word-level similarity between the picture prime and the word fragment. However, most episodespecific frameworks have not examined the actual time course of recovery of different primes, and so although these frameworks are not incompatible with the results reported here, they do not really speak to the finding that words are recovered faster than pictures.

Schacter's (1990, 1992; Tulving \& Schacter, 1990) most recent theoretical formulation incorporates aspects of both the systems and processing views such that different systems are specialized to perform certain processes. He has suggested that priming is a presemantic phenomenon in that it does not depend on semantic encoding operations but is sensitive to changes in perceptual features. He has proposed the existence of perceptual representation systems (PRSs), which process and represent information about the structure and form of various stimuli such as words and objects but do not represent conceptual information about them. However, PRSs do have connections to semantic systems. This theoretical framework can account for the specificity of priming on perceptual tasks as well as for the very weak sensitivity of these tasks to semantic encoding manipulations. The current version of the model does not explicitly address issues about the role of lexical access or the time course of word priming, but it could accommodate the results of Experiment 3 if additional assumptions were made. For example, the word fragments may access the word PRS quickly but take longer to recover information from semantic systems.

We would like to conclude by noting that in regard to the study of memory dissociations, Dunn and Kirsner (1989) and Jacoby (1991) have emphasized the importance of distinguishing between the particular task that the subject performs and the particular cognitive processes that are of interest to the researcher. They warn that confusion will arise when it is assumed that tasks and processes are equivalent. This point is relevant here. Some researchers have expressed distress over the fact that putative data-driven tests show conceptual effects and vice versa. It has been suggested that such findings are problematic for Roediger's (1990; Roediger et al., 1989) version of transfer-appropriate processing, which emphasizes a distinction between data-driven and conceptually driven processing. The debate over the validity of this framework might be a case of mistakenly trying to equate performance on the tests with the operation of a single underlying process. Roediger and his colleagues' (Roediger, 
1990; Roediger \& Blaxton, 1987a, b; Roediger et al., 1989) work has been useful in pointing out two different types of processing that can occur, and Weldon (1991) has suggested that lexical processing might be a third dimension. But it is unlikely that any task represents either a pure perceptual or pure conceptual task, thus it is unlikely that we can devise a perceptual test uncontaminated by conceptual processes (e.g., Masson \& MacLeod, 1992) or a conceptual test uncontaminated by perceptual processes (e.g., Hunt \& Toth, 1990). Schacter and Graf (1989) and Toth and Hunt (1990) have suggested that perceptual and conceptual processing may be too tightly integrated to operate completely independently. This echoes Kolers and Roediger's (1984) point that one's knowledge of something is specific to the means of experiencing itthe procedures of acquisition form an inextricable part of the representation. Thus, the conceptual representation may not be entirely separable from the perceptual analysis or the modality of encoding.

It is important to move beyond the descriptive level of categorizing tasks as one or another type and to examine more precisely how component processes constitute the tasks and what relations exist between these processes and task performance (Dunn \& Kirsner, 1989). Fortunately, recent studies of priming appear to be performing these necessary task analyses. For example, Jacoby (1991) has proposed a methodological framework for assessing the separate contributions of automatic and intentional processes in remembering. Much can be gained from task analyses that seek to decompose tasks into their component processes and to understand how these processes interact in remembering (e.g., Moscovitch, 1984).

\section{REFERENCES}

Bassili, J. N., Smith, M. C., \& MacLeod, C. M. (1989). Auditory and visual word-stem completion: Separating data-driven and conceptually driven processes. Quarterly Journal of Experimental Psychology, 41A, 439-453.

BLAXTON, T. A. (1989). Investigating dissociations among memory measures: Support for a transfer appropriate processing framework. Journal of Experimental Psychology: Learning, Memory, \& Cognition, $15,657-668$.

Brown, A. S., Neblett, D. R., Jones, T. C., \& Mitchell, D. B. (1991). Transfer of processing in repetition priming: Some inappropriate findings. Journal of Experimental Psychology: Learning, Mem ory, \& Cognition, 17, 514-525.

Challis, B. H., \& Brodbeck, D. R. (1992). Level of processing affects priming in word fragment completion. Journal of Experimental Psychology: Leaming, Memory, \& Cognition, 18, 595-607.

D'Agostino, P. R., O'Neill, B. J., \& Paivio, A. (1977). Memory for pictures and words as a function of level of processing: Depth or dual coding? Memory \& Cognition, 5, 252-256.

DunN, J. C., KIRSNer, K. (1989). Implicit memory: Task or process? In S. Lewandowsky, J. C. Dunn, \& K. Kirsner (Eds.), Implicit memory: Theoretical issues (pp. 17-31). Hillsdale, NJ: Erlbaum.

Durso, F. T., \& JoHnson, M. K. (1980). The effects of orienting tasks on recognition, recall, and modality confusion of pictures and words. Journal of Verbal Learning \& Verbal Behavior, 19, 416-429.

Gardiner, J. M., Dawson, A. J., \& Sutton, E. (1989). Specificity and generality of enhanced priming effects for self-generated study items. American Joumal of Psychology, 102, 295-305.
Glisky, E. L., \& Rabinowitz, J. C. (1985). Enhancing the generation effect through repetition of operations. Journal of Experimental Psychology: Learning, Memory, \& Cognition, 11, 193-205.

GRAF, P., \& RYAN, L. (1990). Transfer-appropriate processing for implicit and explicit memory. Journal of Experimental Psychology: Learning, Memory, \& Cognition, 16, 978-992.

Graf, P., \& Schacter, D. L. (1985). Implicit and explicit memory for new associations in normal and amnesic subjects. Joumal of Experimental Psychology: Learning, Memory, \& Cognition, 11, 501-518.

HamanN, S. B. (1990). Level-of-processing effects in conceptually driven implicit tasks. Journal of Experimental Psychology: Learning, Memory, \& Cognition, 16, 970-977.

Hirshman, E., Snodgrass, J. G., Mindes, J., a Feenan, K. (1990). Conceptual priming in fragment completion. Joumal of Experimental Psychology: Learning, Memory, \& Cognition, 16, 634-647.

Hunt, R. R., \& Toth, J. P. (1990). Perceptual identification, fragment completion, and free recall: Concepts and data. Journal of Experimental Psychology: Leaming, Memory, \& Cognition, 16, 282-290. InTRAUB, H. (1979). The role of implicit naming in pictorial encoding. Journal of Experimental Psychology: Learning, Memory. \& Cognition, 5, 78-87

$J_{A C O B Y}$, L. L. (1983). Remembering the data: Analyzing interactive processes in reading. Journal of Verbal Learning \& Verbal Behavior, 22, 485-508.

JACOBY, L. L. (1991). A process dissociation framework: Separating automatic from intentional uses of memory. Journal of Memory \& Language, 30, 513-541.

JACOBY, L. L., \& BROOKs, L. R. (1984). Nonanalytic cognition: Memory, perception, and concept learning. In G. H. Bower (Ed.), The psychology of leaming and motivation: Advances in research and theory (Vol. 18, pp. 1-47). New York: Academic Press.

JACOBY, L. L., \& DALLAS, M. (1981). On the relationship between autobiographical memory and perceptual learning. Joumal of Experimental Psychology: General, 110, 306-340.

Johnston, W. A., DARK, V. J., \& JACOBY, L. L. (1985). Perceptual fluency and recognition judgments. Journal of Experimental Psychology: Learning, Memory, \& Cognition, 11, 3-11.

Kirsner, K., Milech, D., \& Stumpfel, V. (1986). Word and picture identification: Is representational parsimony possible? Memory \& Cognition, 14, 398-408.

KOLERS, P. A. (1975). Specificity of operations in sentence recognition. Cognitive Psychology, 7, 289-306.

Kolers, P. A., \& Roediger, H. L., III (1984). Procedures of mind. Journal of Verbal Learning \& Verbal Behavior, 23, 425-449.

Kroll, J. F., \& Potter, M. C. (1984). Recognizing words, pictures, and concepts: A comparison of lexical, object, and reality decisions. Joumal of Verbal Learning \& Verbal Behavior, 23, 39-66.

Lewandowsky, S., Kirsner, K., Bainbrudge, V. (1989). Context effects in implicit memory: A sense-specific account. In S. Lewandowsky, J. C. Dunn, \& K. Kirsner (Eds.), Implicit memory: Theoretical issues (pp. 185-198). Hillsdale, NJ: Erlbaum.

Masson, M. E. J., \& Freedman, L. (1990). Fluent identification of repeated words. Joumal of Experimental Psychology: Leaming, Memory, \& Cognition, 16, 355-373.

Masson, M. E. J., MacLeod, C. M. (1992). Reenacting the route to interpretation: Enhanced perceptual identification without prior perception. Journal of Experimental Psychology: General, 121, 145-176.

MoNSELL, S. (1985). Repetition and the lexicon. In A. W. Ellis (Ed.), Progress in the psychology of language (pp. 176-189). London: Erlbaum.

Morris, C., Bransford, J. D., \& Franks, J. J. (1977). Levels of processing versus transfer appropriate processing. Journal of Verbal Learning \& Verbal Behavior, 16, 519-533.

Morron, J. (1979). Facilitation in word recognition: Experiments causing change in the logogen model. In P. A. Kolers \& M. E. Wrolstead (Eds.), Processing of visible language (pp. 259-268). New York: Plenum.

Moscovitch, M. (1984). The sufficient conditions for demonstrating preserved memory in amnesia. In L. R. Squire \& N. Butters (Eds.), Neuropsychology of memory (pp. 104-114). New York: Guilford. 
Nelson, D. L. (1979). Remembering pictures and words: Appearance, significance, and name. In L. S. Cermak \& F. I. M. Craik (Eds.), Levels of processing in human memory (pp. 45-76). Hillsdale, NJ: Erlbaum.

Palvio, A. (1971). Imagery and verbal processes. New York: Holt, Rinehart, \& Winston.

Palvio, A. (1986). Mental representation. New York: Oxford University Press.

Palvio, A. (1991). Dual coding theory: Retrospect and current status. Canadian Journal of Psychology, 45, 255-287.

Paivio, A., \& Csapo, K. (1969). Concrete-image and verbal memory codes. Journal of Experimental Psychology, 80, 279-285.

Potter, M. C., \& Faulconer, B. A. (1975). Time to understand pictures and words. Nature, 253, 437-438.

RAJARAM, S., \& RoEDIGER, H. L., III (in press). A direct comparison of four implicit tests of memory. Journal of Experimental Psychology: Learning, Memory, \& Cognition.

RAPPOLD, V. A., \& HaShTroud, S. (1991). Does organization improve priming? Journal of Experimental Psychology: Learning, Memory, \& Cognition, 17, 103-114

Richardson-Klavehn, A., Bjork, R. A. (1988). Measures of memory. Annual Review of Psychology, 39, 475-543.

ROEDIGER, H. L., III (1990). Implicit memory: Retention without remembering. American Psychologist, 45, 1043-1056.

RoEDIGER, H. L., III, \& BLAXTON, T. A. (1987a). Effects of varying modality, surface features, and retention interval on priming in wordfragment completion. Memory \& Cognition, 15, 379-388.

Roediger, H. L., III, \& Blaxton, T. A. (1987b). Retrieval modes produce dissociations in memory for surface information. In D. S. Gorfein \& R. R. Hoffman (Eds.), Memory and learning: The Ebbinghaus centennial conference (pp. 349-379). Hillsdale, NJ: Erlbaum.

Roediger, H. L., III, Weldon, M. S. , \& Chal.LIS, B. H. (1989). Explaining dissociations between implicit and explicit measures of retention: A processing account. In H. L. Roediger III \& F. I. M. Craik (Eds.), Varieties of memory and consciousness: Essays in honour of Endel Tulving (pp. 1-41). Hillsdale, NJ: Erlbaum.

Roediger, H. L., III, Weldon, M. S., Stadler, M. L., \& Riegler, G. L. (1992). Direct comparison of two implicit memory tests: Word fragment and word stem completion. Joumal of Experimental Psychology: Learming, Memory, \& Cognition, 18, 1251-1269.

SCHACTER, D. L. (1990). Perceptual representation systems and implicit memory: Toward a resolution of the multiple memory systems debate. Annals of the New York Academy of Sciences, 608, 543-571.

SCHACTER, D. L. (1992). Understanding implicit memory: A cognitive neuroscience approach. American Psychologist, 47, 559-569.

SChaCtER, D. L., \& GRAF, P. (1989). Modality specificity of implicit memory for new associations. Journal of Experimental Psychology: Learning, Memory, \& Cognition, 15, 3-12.

Smith, E. R., \& Branscombe, N. R. (1988). Category accessibility as implicit memory. Journal of Experimental Social Psychology, 24, 490-504.

Smith, M. C., \& MageE, L. E. (1980). Tracing the time course of picture-word processing. Journal of Experimental Psychology: General, 109, 373-392.

Snodgrass, J. G., \& VANDERWART, M. (1980). A standardized set of 260 pictures: Norms for name agreement, image agreement, familiarity, and visual complexity. Journal of Experimental Psychology: Human Learning \& Memory, 6, 174-215.

SRINIVAS, K., \& Roediger, H. L., III (1990). Classifying implicit memory tests: Category association and anagram solution. Journal of Memory \& Language, 29, 389-412.

Toth, J. P., \& HUNT, R. R. (1990). Effect of generation on a wordidentification task. Journal of Experimental Psychology: Learning, Memory, \& Cognition, 16, 993-1003.

Tulving, E., \& Schacter, D. L. (1990). Priming and human memory systems. Science, 247, 301-306.

WELDON, M. S. (1991). Mechanisms underlying priming on perceptual tests. Journal of Experimental Psychology: Learning, Memory, \& Cognition, 17, 526-541.

WELDON, M. S. (in press). The time course of perceptual and conceptual contributions to priming. Journal of Experimental Psychology: Learning, Memory, \& Cognition.

WELDON, M. S., \& ROEDIGER, H. L., UI (1987). Altering retrieval demands reverses the picture superiority effect. Memory \& Cognition, 15, 269-280.

Weldon, M. S., Roediger, H. L., II, \& Challis, B. H. (1989). The properties of retrieval cues constrain the picture superiority effect. Memory \& Cognition, 17, 95-105.

\section{NOTES}

1. Implicit tests refer to those that do not require conscious recollection of a prior study episode. Memory is measured by the amount of priming, which is the facilitation or bias in responding that results from previous exposure to test-relevant material. Implicit tests are distinguished from explicit tests, which require conscious recollection (see Graf \& Schacter, 1985; Richardson-Klavehn \& Bjork, 1988). Many interesting theoretical issues attend the distinction between implicit and explicit memory tests (e.g., Roediger, 1990; Schacter, 1992), but the focus here is on the type of processing underlying performance on an implicit perceptual test-namely, word-fragment completion.

2. Although word-fragment completion is an implicit test, we use the term "retrieval" to capture the idea that priming results from the recovery of a prior encoding episode. Retrieval need not be conscious or deliberate.

(Manuscript received July 17, 1992; revision accepted for publication January 25,1993 .) 